\title{
An ABPA Case with an Initial Diagnosis and Treatment of Smear-Negative Pulmonary Tuberculosis
}

\author{
Şeyma Özden 1, Arzu Deniz², Naciye Mutlu², Hüseyin Cem Tigin², Murat Kıyık ${ }^{2}$ \\ ${ }^{1}$ Department of Chest Disease, Sultan Abdulhamid Han Training and Research Hospital, Istanbul, Turkey \\ ${ }^{2}$ Department of Chest Disease, Yedikule Chest Diseases and Chest Surgery Training and Research Hospital, Istanbul, Turkey
}

\begin{abstract}
Allergic bronchopulmonary aspergillosis (ABPA) is a hypersensitive reaction to a fungus known as Aspergillus fumigatus. The differential diagnosis for ABPA is generally not considered before diagnosis and treatment of smear-negative pulmonary tuberculosis. In this study, we present an example case and aim to remind of ABPA. A patient with a history of asthma had increasingly developed shortness of breath and wheezing during asthma treatment. The patient was initially diagnosed with pneumonia based on pulmonary infiltration findings on PA x-ray. Antibiotherapy did not relieve the symptoms, and acid-fast bacteria (AFB) culture was negative. Upon detection of a progression of pulmonary infiltration on the second PA $x$-ray image, following the antibiotherapy, treein-bud (TIB) opacities and cavitary lesion were observed on computed tomography (CT) of the thorax and the patient was clinically and radiologically diagnosed with tuberculosis. Due to not observing any relief of symptoms after tuberculosis treatment and earlier findings, such as high level of total immunoglobulin E (IgE), presence of peripheral eosinophilia, diagnosis of central bronchiectasis on thorax CT image, positive Aspergillus skin test results and history of asthma, allergic bronchopulmonary aspergillosis (ABPA) was considered and verified by cytologic examination of specimens obtained through fiberoptic bronchoscopy (FOB).
\end{abstract}

Keywords: Allergic bronchopulmonary aspergillosis; asthma; pulmonary tuberculosis.

A llergic bronchopulmonary aspergillosis (ABPA) is a hypersensitivity reaction of the lung caused by a latephase inflammatory response allergic to the antigens of Aspergillus fumigatus colonized in bronchial secretions of patients with asthma and cystic fibrosis [1]. Aspergillus species are commonly found in nature; they live in rotten organic matter, straw, dust, water and food ${ }^{[2]}$. There are more than 900 Aspergillus strains in the world, but Aspergillus fumigatus, Aspergillus niger and Aspergillus flavus are the most common infectious species of aspergillus species. Aspergillus spores, 2-3 $\mathrm{mm}$ in size, become a constant source of antigen in the airways by inhalation and stimulate the immune system, causing damage to the bronchial wall. This destruction may cause invasive aspergillosis, aspergilloma, IgE-mediated allergic rhinitis and asthma, hypersensitivity pneumonia, chronic, necrotizing pneumonia and allergic bronchopulmonary aspergillosis (ABPA) in the respiratory system ${ }^{[3]}$. ABPA was first described in 1957 by Hinson et al. ${ }^{[4]}$. Although asthma is a frequently diagnosed disease, ABPA is not often considered in patients with uncontrolled asthma ${ }^{[5]}$. The prevalence of ABPA is known to be $1-2 \%$ in patients with asthma and $10 \%$ in patients with

Correspondence (iletişim): Şeyma Özden, M.D. Sultan Abdulhamid Han Egitim ve Arastirma Hastanesi, 34668, Uskudar, Istanbul, Turkey Phone (Telefon): +90 5053954926 E-mail (E-posta): seymaglhn@hotmail.com 
cystic fibrosis ${ }^{[6]}$. In this study, we present a case of ABPA who was diagnosed with pulmonary tuberculosis clinically and radiologically and who had been treated with tuberculosis for two and a half months.

\section{Case Report}

A 29-year-old female patient had been known to have a diagnosis of asthma for 15 years. The patient had been treated as asthma for the last four months; she had been using high dose inhaled steroid, long-acting beta 2 agonist and leukotriene receptor antagonist.

While under treatment, he had applied to the outpatient clinic with complaints of dyspnea, wheezing, expectoration of dark brown and sticky sputum for the last one month. White blood cell counts $\left(5.900 / \mathrm{mm}^{3}\right)$, hemoglobin $(13.1 \mathrm{~g} /$ dl), Hct: (39.9\%), eosinophil counts (5.1\%) and blood biochemistry results were within normal limits.

After bilateral patchy infiltrations were detected on the posteroanterior (PA) chest X-ray, antibiotherapy was initiated with a preliminary diagnosis of pneumonia. Thoracic CT was performed because of the absence of any regression in the patient's complaints after 15 days, and the persistence of patchy infiltrations on the control chest X-ray. Thoracic CT scan revealed diffuse mosaic perfusion pattern in both lungs, thick asymmetric walled cavitary lesions the largest being $2 \mathrm{~cm}$ in diameter in the right lung upper lobe anterior and posterior segments, left lung upper lobe anterior and lingular segments, right lung lower lobe superior segment, and dense adjacent areas of alveolarinterstitial consolidation, budding tree patterns, and central bronchiectasis and diffuse bronchiolitis (Figs. 1, 2). The patient was thought to have pulmonary tuberculosis, and

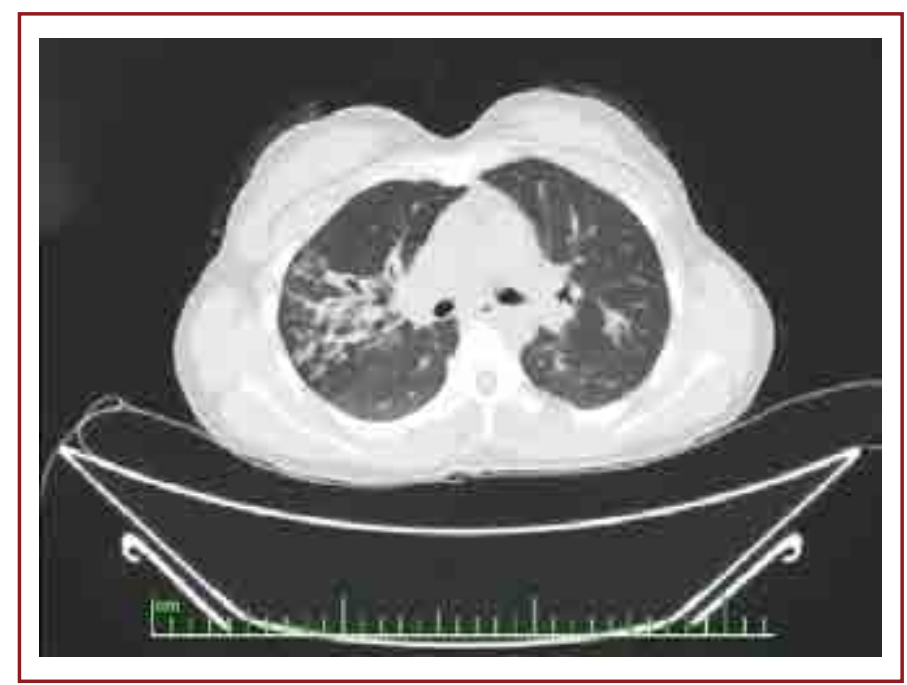

Figure 1. Thoracic tomogram at the first presentation of the patient. sputum ARB was requested. Although ARB was found to be negative twice in direct examination, the clinic of the patient did not improve, and as a result of clinicoradiological evaluation, the patient was accepted as smear-negative pulmonary tuberculosis and anti-tuberculosis treatment was initiated (Fig. 3).

The patient developed nausea and vomiting approximately one month after the initiation of tuberculosis treatment, and liver function test (LFT) results were found to be high; thus, anti-tuberculosis treatment was discontinued for one week. Tuberculosis treatment was resumed when LFT decreased to normal values. Approximately two and a half months after the treatment was started, the patient presented to us with nausea and vomiting again, and her

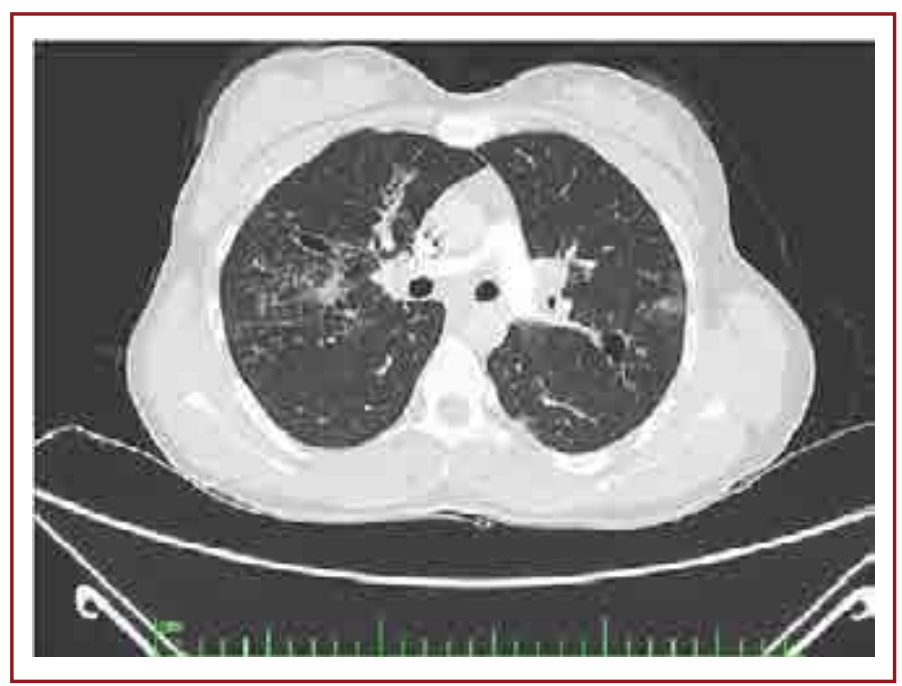

Figure 2. Thoracic tomogram at the first presentation of the patient -2 .

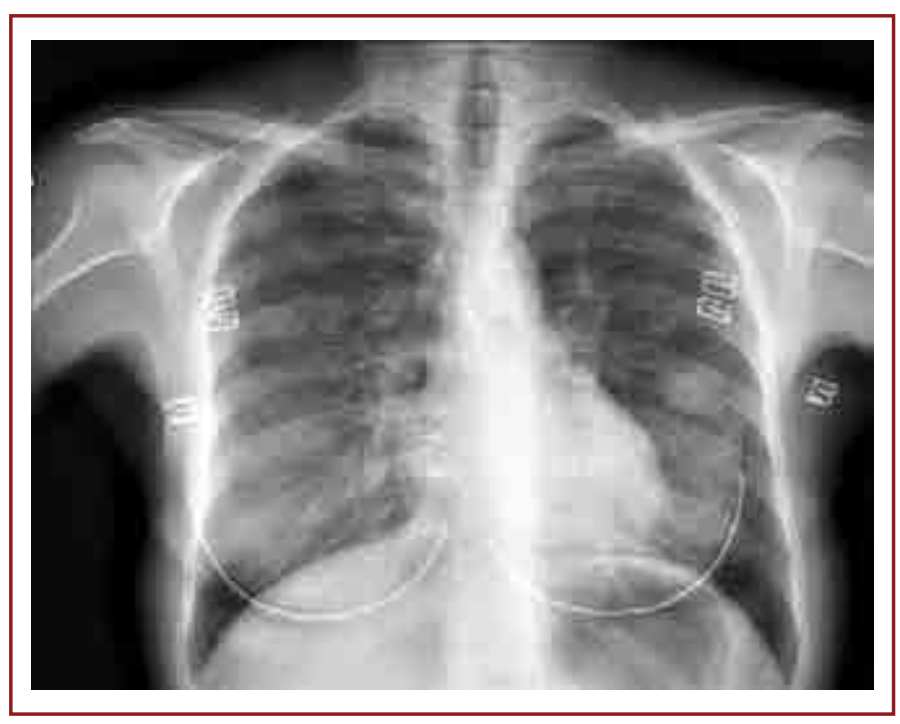

Figure 3. PA chest X-ray when the decision to start tuberculostatic treatment was made. 
LFT values were increased again. Meanwhile, tuberculosis treatment was discontinued at the end of 2.5 months due to the absence of growth in sputum ARB culture and progression on PA chest X-ray (Fig. 4). The patient's eosinophil count was $13.2 \%(0-5 \%)$ and total IgE was $1775.2 \mathrm{IU} / \mathrm{ml}$ (0-100). Fiber optic bronchoscopic examination (FOB) was decided. Right and left bronchial system was normal and open to the subsegments in FOB. BAL and TBB were performed from the left lingular segment.

BAL cell profile was reported as follows: lymphocyte, $1 \%$, PNL, 80\%; eosinophil 3\%; macrophage, $16 \%$. Pathological examination of the materials obtained by bronchoscopy revealed septate fungal hyphae structures consistent with Aspergillus stained with Grocott stain in an area of the cell block of bronchoalveolar lavage. Aspergillus skin test was positive for an area of $7 \times 10 \mathrm{~mm}$. When clinical and laboratory findings were reviewed, in addition to a history of asthma, based on eosinophilia, total IgE elevation, presence of central bronchiectasis and positive skin test for aspergillus antigen, septate fungal hyphae structures compatible with aspergillus in lavage sample retrieved using a bronchoscope and the patient was diagnosed as ABPA. Then, oral-systemic steroid treatment was initiated with daily doses of $48 \mathrm{mg}$. Two weeks after the initiation of treatment, at the control visit steroid dose was gradually

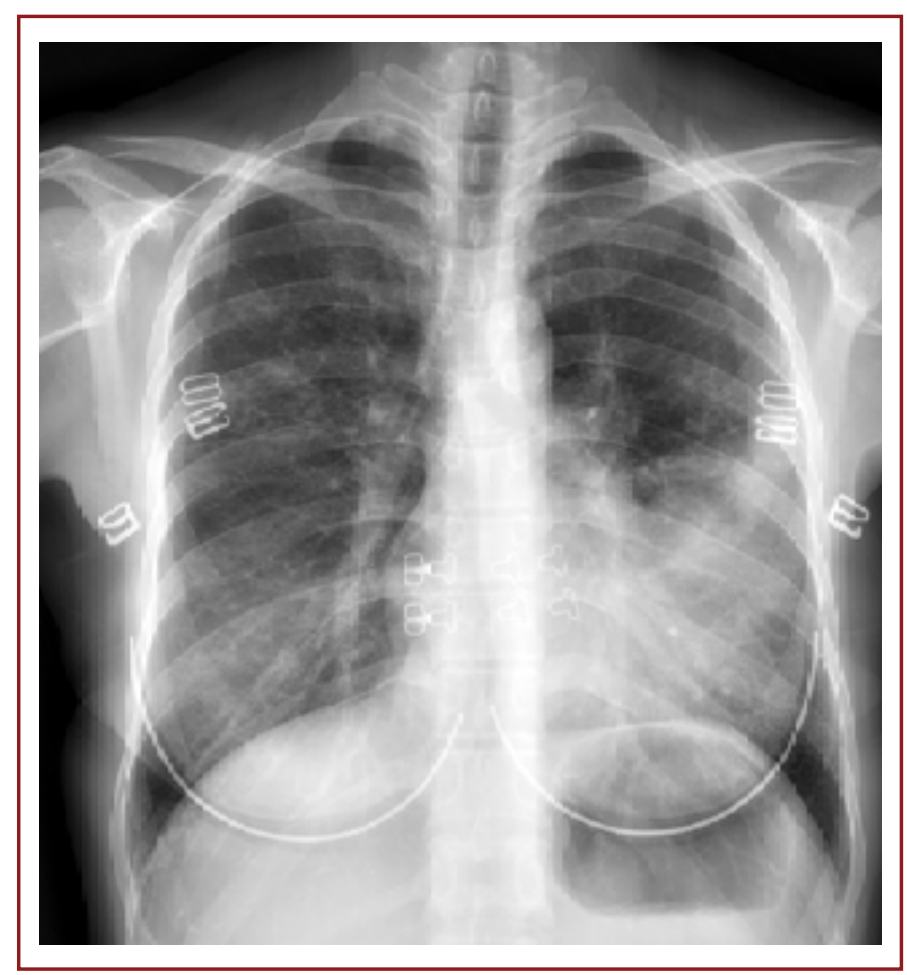

Figure 4. PA chest X-ray two and a half months after initiation of $\mathrm{Tb}$ treatment. decreased due to a significant improvement in her complaints and a tendency to decrease in total lgE. Significant regression was found in the chest $X$-ray of the patient in the first month of the treatment (Fig. 5).

When the patient completed the first month of steroid treatment, no steroid-related side effects were detected during this period. Steroid treatment was planned to be completed in three months.

\section{Discussion}

ABPA is an immunological reaction to chronic colonization of airways with Aspergillus and other fungal pathogens. Although ABPA occurs most frequently in young adults, there are also reported cases in childhood ${ }^{[7]}$. The diagnosis may be delayed because most of the clinical and serological diagnostic criteria of ABPA, especially in patients with cystic fibrosis, overlap with the underlying disease.

Delay in diagnosis leads to fibrotic lung disease in advanced cases ${ }^{[8]}$. Diagnostic criteria of ABPA were first identified by Rosenberg et al. ${ }^{\text {9] }}$ in 1977 as eight criteria (Table 1). Although at first, ABPA was thought that the patient should have all of these criteria to be diagnosed, but this approach prolonged the diagnostic process. Vlahakis et al. [10] defined new diagnostic criteria in 2001 (Fig. 1). In our case, six of the eight criteria were positive. Aspergillus fumigatus precipitant antibody and Aspergillus specific lgE and IgG antibody could not be studied in our center; thus, these tests could not be evaluated in our patient.

After the diagnosis of ABPA, clinical staging will guide clinicians to plan treatment. ABPA was considered in five

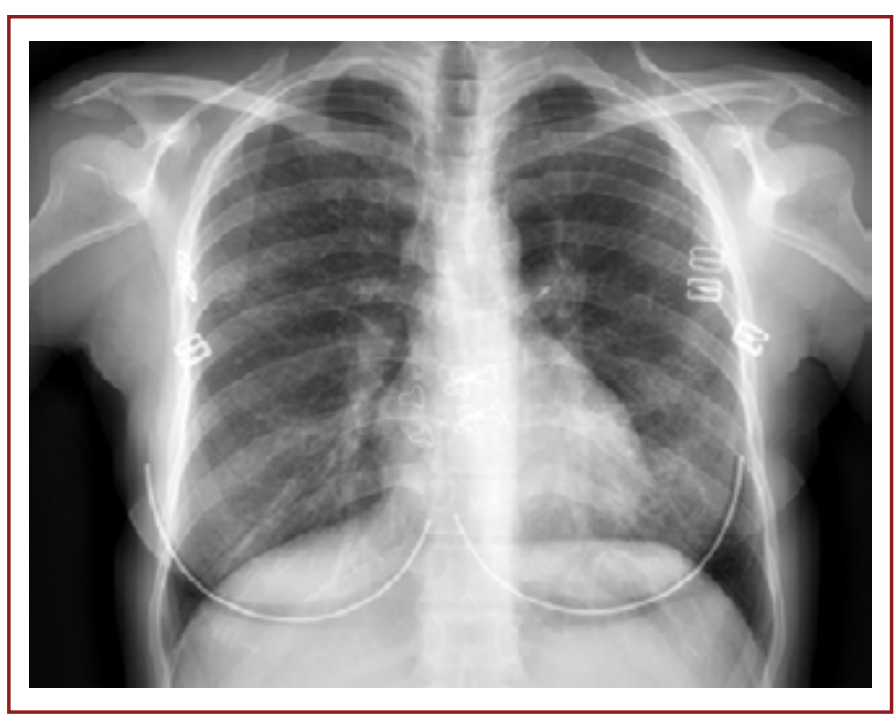

Figure 5. Control PA chest X-ray one month after initiation of steroid treatment upon diagnosis of ABPA was made. 


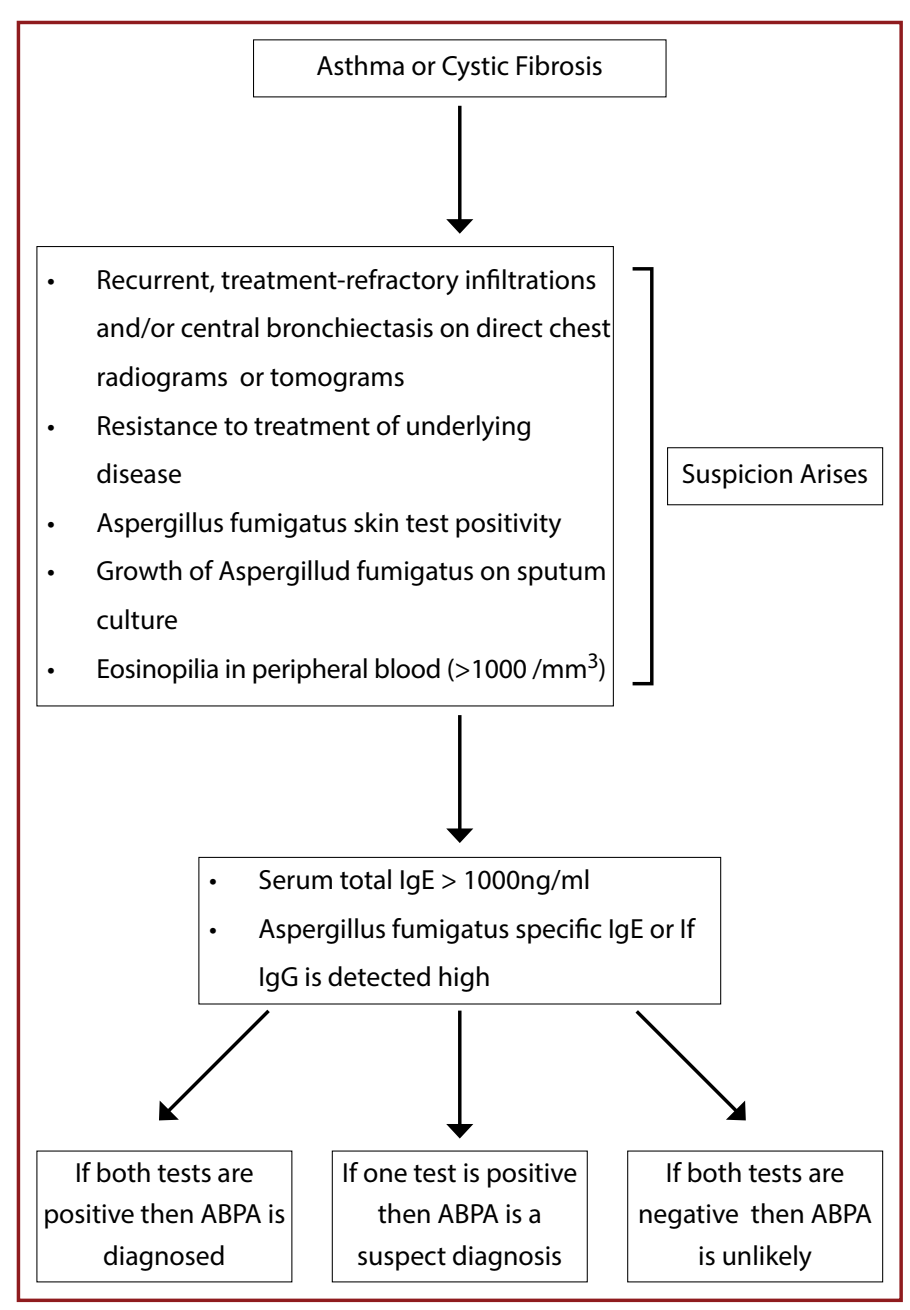

Figure 6. Neuromuscular monitorization.

Table 1. ABPA criteria formulated by Rosenberg et al.

- Asthma or cystic fibrosis

- Eosinophilia in peripheral blood

- $\mathrm{AF}$ (A. fumigatus) skin test positivity

- AF precipitant antibody positivity

- Serum total lgE $>1000 \mathrm{ng} / \mathrm{ml}$

- Central bronchiectasis

- Transient or persistent infiltrations on direct PA chest X- ray

- AF specific IgE and IgG antibody positivity

stages (Fig. 6). We evaluated our case as stage 4 ABPA because of persistent severe asthma, total IgE elevation and pulmonary infiltration.

When we look at the radiological features of ABPA, ABPA may present with very variable conditions. In the acute stage, wandering transient infiltrations, mucus plugs and atelectasis that regress spontaneously or with steroid therapy are seen. Irreversible bronchial damage and bronchiectasis develop later on ${ }^{[11]}$. Bronchiectasis is typically of a cylindrical type with central involvement. Also, in our case, the presence of diffuse central bronchiectasis supported the diagnosis of ABPA. In addition, radiological findings may vary. There are cases with ABPA followed up with the diagnosis of lung cancer because of a presence of fullness in the hilar region, and central mass appearance in thorax CT that narrows and obliterates the upper lobe bronchus, [12]. Although rare, pulmonary fibrosis, bleb, pneumothorax, emphysematous changes, ground glass appearance, pleural effusion, pleural thickening, aspergilloma, fibrocavitary lesions can be seen radiologically. In our case, due to the presence of central bronchiectasis, cavitary lesion and budding tree appearance on thorax $\mathrm{CT}$, the patient was initially evaluated clinically and radiologically as smear- negative pulmonary tuberculosis.

ABPA treatment has two main components: controlling inflammation damaging lung tissue with systemic corticosteroid treatment and reducing fungal antigen burden by antifungal treatment ${ }^{[13]}$. Steroid treatment is started at 0.5 $2 \mathrm{mg} / \mathrm{kg} /$ day (maximum daily dose $60 \mathrm{mg}$ ). After 1-2 weeks, the steroid dose is gradually reduced by evaluating symptoms, spirometric, and radiographic findings and serum IgE levels. A $30-50 \%$ reduction in IgE levels is considered significant. IgE levels need to be monitored throughout treatment. At the end of the third month, treatment may be discontinued. If the response to steroid therapy is poor, relapse occurred, or if steroid-related side effects develop, itraconazole should be added to antifungal drugs. The use of itraconazole reduces the need and duration of steroid use ${ }^{[13,14]}$. Itraconazole is used in a single dose of $5 \mathrm{mg} / \mathrm{kg} /$ day. The maximum dose is $400 \mathrm{mg} /$ day, and the duration of treatment should be 3-6 months. Liver function tests should be performed one month after the initiation of itraconazole treatment and values should be monitored every 3-6 months ${ }^{[13]}$. Some clinicians prefer to use voriconazole instead of itraconazole for invasive pulmonary aspergillus forms. In the literature, there are studies showing that voriconazole is also successful in the treatment of ABPA. Voriconazole is used for maintenance therapy after a loading dose of $400 \mathrm{mg}$ for the first two doses and $200 \mathrm{mg}$ twice daily for maintenance.

Liver function tests should be followed as in itraconazole treatment [15-17]. Although there are not enough studies showing that voriconazole is superior to itraconazole, voriconazole has better gastrointestinal tolerance which is its established advantage.

Another treatment option in the treatment of ABPA, especially in poorly controlled asthmatic patients, is omal- 
izumab. In the treatment of asthma, omalizumab dose is adjusted according to serum IgE levels, whereas it is difficult to regulate its dose because of already higher serum IgE levels in ABPA. Based on clinical experience, and a limited number of studies, subcutaneous $375 \mathrm{mg}$ omalizumab twice a month is another alternative treatment option in ABPA cases ${ }^{[18-21]}$.

Although ABPA is a rarely seen disease, ABPA should be considered in the differential diagnosis in patients whose pulmonary infiltrations do not regress despite antibiotherapy, and in cases where ARB is directly negative, especially in patients with central bronchiectasis. Early diagnosis and appropriate treatment prevent the development of bronchiectasis and end-stage lung disease ${ }^{[22]}$.

\section{Conclusion}

In conclusion, we wanted to present this case to emphasize that ABPA should be considered in differential diagnosis, especially in patients with asthma or bronchiectasis before clinical and radiological diagnosis of smear- negative pulmonary tuberculosis should be taken in detail, especially in uncontrolled asthma patients.

Informed Consent: Approval was obtained from the patients. Peer-review: Externally peer-reviewed.

Conflict of Interest: None declared.

Authorship Contributions: Concept: M.K.; Design: A.D.; Data Collection or Processing: Ş.Ö.; Analysis or Interpretation: N.M.; Literature Search: H.C.T.; Writing: Ş.Ö.

Financial Disclosure: The authors declared that this study received no financial support.

\section{References}

1. Tillie-Leblond I, Tonnel AB. Allergic bronchopulmonary aspergillosis. Allergy 2005;60:1004-13.

2. Soubani $\mathrm{AO}$, Chandrasekar $\mathrm{PH}$. The clinical spectrum of pulmonary aspergillosis. Chest 2002;121:1988-99.

3. Patterson TF. Aspergillus species. In: Mandell GL, Bennett JE, Dolin R (editors). Mandell, Douglas, and Bennett's principles and practice of infectious diseases. 8th ed. Philadelphia: Elsevier Churchill Livingstone; 2015:2895-2908.

4. Hinson KF, Moon AJ, Plummer NS. Bronkopulmonary aspergillosis. a reviewand eight cases. Thorax 1952;7:317-33.

5. Aydoğan Ö, Erdinç M, Aytemur ZA, Sin A, Savaş S. Orta ve ağır astımlı olgularda allerjik bronkopulmoner aspergilloz. Türk Toraks Dergisi 2008;9:151-6.

6. Greenberger PA, Patterson R. Allergic bronchopulmonary as- pergillosis and the evaluation of the patient with asthma. J Allergy Clin Immunol 1988;81:646-50.

7. Slavin RG, Laird TS, Cherry JD. Allergic bronchopulmonary aspergillosis in a child. J Pediatr 1970;76:416-21.

8. Shah A, Panjapi C. Allergic bronchopulmonary aspergillosis:a review of a disease with a worldwide distribition. J Asthma 2002;39:273-89.

9. Rochester CL. The eosinophilic pneumonias. In: Fishman AP (editor). Pulmonary diseases and disorders. 3rd ed. NewYork: Mc Graw Hill, 1998:1133-50.

10. Vlahakis NE, Aksamit TR. Diagnosis and treatment of allergic bronchopulmonary aspergillosis. Mayo Clin Proc 2001;76:930 8.

11. Yıldırım N, Topal U. Pulmoner aspergilloz: değişken radyolojik bulgular. Tanısal ve Girişimsel Radyoloji 2004;10:121-6.

12. Uğurman F, Gözü A, Göçmen S, Akkalyoncu B, Önde G, Samurkaşoğlu $B$. Akciğerde kitle görünümü veren bir alerjik bronkopulmoner aspergillozis olgusu. Akciğer Arşivi 2003;4:217-20.

13. Antibiotic Treatment for Cystic Fibrosis. 3rd edition. Report of the UK Cystic Fibrosis Trust Antibiotic Working Group, 2009.

14. Hatziagorou E, Walsh TJ, Tsanakas JN, Roilides E. Aspergillusand the paediatric lung. Paed Respir Rev 2009;10:178-85.

15. Erwin GE, Fitzgerald JE. Case report: allergic bronchopulmonary aspergillosis and allergic fungal sinusitis successfully treated with voriconazole. J Asthma 2007; 44:891-5.

16. Glackin L, Leen G, Elnazir B, Greally P. Voriconazole in the treatment of allergic bronchopulmonary aspergillosis in cystic fibrosis. Ir Med J 2009;102:29.

17. Chishimba L, Niven RM, Cooley J, Denning DW. Voriconazole and posaconazole improve asthma severity in allergic bronchopulmonary aspergillosis and severe asthma with fungal sensitization. J Asthma 2012;49:423-33.

18. Li JX, Fan LC, Li MH, Cao WJ, Xu JF. Beneficial effects of Omalizumab therapy in allergic bronchopulmonary aspergillosis: A synthesis review of published literature. Respir Med 2017;122:33-42.

19. Voskamp AL, Gillman A, Symons K, Sandrini A, Rolland JM, et al. Clinical efficacy and immunologic effects of omalizumab in allergic bronchopulmonary aspergillosis. J Allergy Clin Immunol Pract 2015;3:192-9.

20. Randhawa I, Chin T, Nussbaum E. Resolution of corticosteroidinduced diabetes in allergic bronchopulmonary aspergillosis with omalizumab therapy: a novel approach. J Asthma 2009;46:445-7.

21. Lin RY, Sethi S, Bhargave GA. Measured immunoglobulin E in allergic bronchopulmonary aspergillosis treated with omalizumab. J Asthma 2010; 47:942-5.

22. Tonnel AB, Tillie-Leblond I. [Refractory asthma: diagnosing allergic bronchopulmonary aspergillosis].[Article in French]. Presse Med 2008;37:161-6. 